\title{
Expanding Grof's Concept of the Perinatal: Deepening the Inquiry into Frightening Near-Death Experiences
}

\author{
Christopher M. Bache, Ph.D. \\ Youngstown State University
}

\begin{abstract}
This study suggests that in order to explain the phenomenology of perinatal experience, as described in the work of Stanislav Grof, we must hypothesize that the patient in these instances has expanded beyond the individual subject. Rupert Sheldrake's concept of morphic fields is incorporated to suggest that the patient in these sessions might best be conceptualized as the species itself, or the morphic field of the species mind. Possible explanations for Grof's tilt toward personal psychology in his presentation of perinatal dynamics are explored. The implications of this expansion of perinatal theory for understanding frightening near-death experiences is summarized.
\end{abstract}

In a previous paper in this Journal, I proposed a perinatal interpretation of frightening near-death experiences (NDEs), arguing that all three forms of frightening NDEs-inverted, hellish, and meaningless void experiences-can be understood as rooted in the perinatal level of consciousness (Bache, 1994). In that project, Stanislav Grof's formulation of the perinatal dimension was accepted as it stood and applied to the problem of frightening NDEs. I wish to deepen that analysis by now turning a critical eye to Grof's concept of the perinatal itself. I will critique Grof's description of the perinatal level of consciousness and propose an expansion of the concept. If successful,

Christopher M. Bache, Ph.D., is Professor of Philosophy and Religious Studies at Youngstown State University. Reprint requests should be addressed to Dr. Bache at the Department of Philosophy and Religious Studies, Youngstown State University, Youngstown, OH 44555-3448. 
this exercise in transpersonal theory will in turn deepen our understanding of the dynamics of frightening NDEs.

In his many books, Grof has documented the perinatal level of consciousness as a domain in which the personal and transpersonal dimensions intersect and blend in a complex fashion. While never allowing the perinatal to be conceptualized reductively as the mere reliving of one's biological birth, his analysis of perinatal dynamics has nevertheless listed strongly toward the personal side of the equation, leaving important transpersonal dynamics unexplained. The purpose of this study is to attempt to correct this imbalance by suggesting a rationale for the appearance of transpersonal phenomena in perinatal experiences that goes beyond Grof's formulation. Toward this end I will identify a set of questions left unaddressed in Grof's account and will draw upon Rupert Sheldrake's theory of formative causation and morphic fields to outline answers to these questions. This expansion of theory will not negate Grof's detailed and powerful analysis of the Basic Perinatal Matrices, but is intended as a step toward a more balanced account of this complicated domain. If we can advance Grof's discussion, it is only because we live in an intellectual environment that his many books have helped create.

\section{The Problem}

There is a subtle ambiguity in Grof's account of the perinatal that runs throughout his books. On the one hand, perinatal experience is defended as being a category of experience that is sui generis and not reducible to personal categories (Grof, 1975, 1980, 1988), while on the other hand the burden of Grof's explanation of perinatal experience lists decidedly in the direction of personal psychology. He has demonstrated that perinatal experience intertwines personal and transpersonal experiences and represents a dynamic interpenetration of these two levels of consciousness. We would expect, therefore, that a complete explanation of perinatal experience would be balanced between these two modes, that it would explain as much in one direction as it does in the other. What we find, however, is an explanation that works out the logic of the personal side of perinatal experience in considerably greater detail than the transpersonal side. No matter how many times he reminds us that perinatal experiences cannot be reduced to the birth trauma, the sheer volume of explanation that he provides in that direction cannot help but leave the reader thinking 
of the perinatal disproportionately in terms of biological birth. The very name "perinatal" reinforces this tendency.

Indeed, Grof's phrasing in key passages supports this inclination. For example, in Beyond the Brain (1985), he writes: "The central element in the complex dynamics of the death-rebirth process seems to be reliving the biological birth trauma" (p. 140). If the birth trauma is "central," then the transpersonal components of perinatal experience are not central and must represent some sort of overlay on this more fundamental core. This is not, in fact, a mere semantic lapse but accurately reflects the general direction of Grof's analysis. He convincingly demonstrates that the patterns of physical and psychological perinatal symptomatology mirror in a condensed and overdetermined fashion the experiences of the fetus before, during, and after delivery. Meanwhile, the logic of the appearance of transpersonal perinatal experiences is not explained except as constituting an experiential parallel to biographical experience. Even while acknowledging that individual subjects may experience the perinatal level almost entirely in philosophical or spiritual terms, the thrust of Grof's analysis to date is to see biographical experiences as forming the thematic core of perinatal experience and to view transpersonal experiences as drawn in through a form of thematic resonance.

Because this is an important point, let me allow Grof himself to make it. Of the many places where he discusses the complex relation of transpersonal and personal elements in perinatal experience, the most complete account appears in The Adventure of Self-Discovery (1988). After reminding the reader that the perinatal process transcends biology and that we must avoid the trap of seeing birth as an all-explanatory principle, he goes on to summarize various transpersonal aspects of perinatal experience. He describes the unconscious at the perinatal level as being organized into highly condensed systems (COEX systems) that store our experiences in thematically congruent clusters. Here he writes:

The perinatal unfolding is also frequently accompanied by transpersonal experiences, such as archetypal visions of the Great Mother or the Terrible Mother Goddess, hell, purgatory, heaven or paradise, identification with animals, and past incarnation experiences. As it is the case with the various associated COEX systems, the connecting link between these transpersonal phenomena and the BPM's is similarity of the emotions or physical sensations involved..... Identification with the fetus in various stages of the birth process seems to provide selective access to themes in the transpersonal domain that involve similar emotional states and psychosomatic experiences. 
Some of these themes have the form of archetypal sequences; others depict situations from the collective memory banks of humanity, or even from the holographic archives of nature related to the animal, vegetable, or mineral kingdoms. (pp. 10-11)

This explanation, however, left an important problem unaddressed: namely, what therapeutic role do these experiences have? Why should persons who are engaging unresolved fetal trauma get involved in torturous experiences of collective suffering or excruciatingly painful archetypal sequences? In asking this question, I am assuming, of course, that these experiences do in fact have a therapeutic function, that their appearance is not simply accidental or random. This assumption seems warranted by the consistency with which these thematically related experiences have surfaced at approximately the same point in the therapies of thousands of subjects. Grof's explanation that persons are drawn into these experiences through the similarity of emotional content or physical sensations helps us understand how this happens but not why. He documents that these painful encounters are extremely beneficial for the individuals involved, as they are part of the death-rebirth experience, but by itself this is not a sufficient explanation of the phenomenon. It leaves unanswered the fundamental question: Why should the engagement of collective suffering of this magnitude be part of an individual's deathrebirth process at all?

The press to answer this question comes from the fact that the levels of suffering reached in these transpersonal episodes are many times greater than anything deriving from the personal level of the psyche. Even taking into account the compounding effect of COEX systems (Grof, 1975), transpersonally rooted perinatal pain is so much more severe than personally rooted perinatal pain as to represent a quantum jump in agony.

An example will help illustrate this point. The following account, not previously published, came from the perinatal segment of an advanced high-dose lysergic acid diethylamide (LSD) session of a welleducated professional:

I was caught up in a horror that I am incapable of describing with any accuracy. It was a raging insanity, a surging kaleidoscopic field of chaos, pain, and destruction. It was as if the entire human race had gathered from all corners of the globe and gone absolutely stark raving mad. They were attacking each other with a rabid savagery augmented by science fiction technology. There were many currents crossing and crisscrossing in front of me, each composed of thousands of people, some currents killing in multiple ways, some being 
killed, some fleeing in panic, others being rounded up, others witnessing and screaming in terror, others witnessing and having their hearts broken by a species gone mad-and " $\mathrm{I}$ " was all their experiences. I was not me in any personal sense but had expanded to include thousands, even millions of persons. The magnitude of the deaths and the insanity is impossible to describe. Every time I try even now, I break down in tears.

I keep trying to conceptually grasp the content of the pain and I keep failing. The problem is finding a frame of reference. The only categories I have available to me are simplistic approximations that can give only a vague sense of it. The suffering comprises all of human history. It is at once species-specific and archetypal. It comprises the wildest science fiction worlds of horror beyond your imagination. It involves not only human beings but billions and billions of pieces of matter in agonizing galactic explosions. Horror beyond any scope. It is a convulsing of the human species, a convulsing of the universe. Floating through it were scenes of tragic suffering caused by nature and human indifference. Thousands of starving children from around the globe, their bodies bloated in death, their eyes staring out blankly at a humanity that was killing them through systemic ecological abuse and human neglect. Lots of violence between men and women-rape, beatings, intimidation, retaliation-cycles and cycles of destruction.

When one is immersed time and again through many sessions into torment such as this, one must answer the question: "Why is this happening? How is this a meaningful part of my therapeutic process?" The absence of an answer to this question, indeed, the absence of the question itself stands in stark contrast to the depth of explanation Grof provides for the personal roots of the perinatal ordeal. On this side of the ledger, his analysis is subtle and penetrating. It is on the transpersonal side that his presentation, as rich and detailed as it is, is incomplete.

Let me insert a brief clarification. Past incarnation experiences represent a complicated intermediate case between personal and transpersonal phenomena. On the one hand, they are transpersonal-and this is how Grof classified them-because they reach beyond the personal body/mind identity of the present incarnation. On the other hand, they are unlike many other transpersonal experiences in that they constitute part of one's extended individual existence. They are experienced as being "mine" while not being my current me; they are part of my distinctive lineage. For the purposes of this study, therefore, I suggest that we classify past incarnation experiences on the personal side of the ledger, in the sense of the "extended personal." The kind of perinatal experiences that I am con- 
cerned to understand are those that reach beyond one's individual karmic history, such as those summarized by Grof in the following passage:

A subject can experience himself as thousands of soldiers who have died on the battlefields of the whole world from the beginning of time, as the tortured victims of the Spanish Inquisition, as prisoners of concentration camps, as patients dying of terminal diseases, as aging individuals who are decrepit and senile, as mothers and children dying during delivery, or as inmates maltreated in chronic wards of insane asylums. (1975, p. 116)

The question I am pressing in this study is this: What is the therapeutic value of undergoing such experiences? If a person is caught up in this kind of collective suffering through some form of emotional or physical resonance with the birth experience, what therapeutic function does it have? Where is its therapeutic effect focused and to what end? If we can answer this question, we might in turn gain additional insight into the possible therapeutic efficacy of frightening NDEs.

To anticipate somewhat, I will suggest below that in order to answer these questions we must look beyond the individual subject who is having these experiences to the collective group that he or she is part of. We must enlarge our definition of the patient to include the entire human species. We are assisted in making this conceptual jump by drawing upon Rupert Sheldrake's concept of morphic fields, which in this context can be seen as a refinement of Carl Jung's notion of the collective unconscious.

By way of contrast, Grof always discusses the therapeutic impact of the death-rebirth experience solely in terms of the individual patient. He consistently focuses our attention on the psychospiritual transformation of the individual undergoing the experience, and in a few instances on the transformation of the subject's karmic antagonist (1985, 1988). In LSD Psychotherapy (1980), for example, Grof writes:

Activation of the destructive and self-destructive potential in the individual [italics added] is one of the most important aspects of the death-rebirth struggle. Scenes of unbridled aggression and mass destruction, as well as sadomasochistic orgies, are standard components of the perinatal unfolding. In this context, enormous amounts of destructive energy are mobilized and discharged: the result is a dramatic reduction of aggressive feelings and tendencies. (p. 281) 
Later, in Beyond the Brain (1985), when he is summarizing the spiritual repercussions of experiential psychotherapy, the entire discussion revolves around the individual with no mention of the possibility that larger fields encompassing the individual might be affected. Similarly, in The Adventure of Self-Discovery (1988), Grof states that experiencing the death-rebirth sequence and reconnecting with the intrinsic spiritual dimension of the psyche is "conducive to profound changes in the philosophical and spiritual belief system, basic hierarchy of values, and general life strategy" [of the individual] (p. 9).

This focus on the spiritual evolution of the individual is another indication of Grof's tilt toward the personal. Granted, the evolution he is describing was an evolution in which the individual transcends his or her personal identity, but this is precisely what creates the ambiguity in Grof's presentation. The death-rebirth sequence culminates in the discovery that one is, at deeper levels, much more than the body/mind self, yet Grof's discussion of the impact of this discovery consistently focuses our attention on the individual subject.

Having outlined some questions left unaddressed in Grof's account, let me turn to attempt some answers. In doing so I want to emphasize that I see this project not as subtracting anything from Grof's analysis but as extending it by making it more consistent with itself.

\section{Rethinking the Perinatal}

It is increasingly common today for transpersonally informed writers to speak almost matter-of-factly of three "levels" of consciousness: the personal, perinatal, and transpersonal. While Grof himself has standardized these categories, he also makes it clear that the perinatal does not have the same status as the other two levels, for the simple reason that it does not endure. Perinatal symptomatology eventually consumes itself in experientially oriented psychotherapies and disappears. Over the course of extended therapy, subjects eventually cease to experience perinatal complications, as the transition to transpersonal states of awareness becomes less problematic. While it is operationally active, the perinatal domain appears as an intersection of personal and transpersonal levels, possessing characteristics of each.

As a heuristic device, therefore, let us model consciousness in terms of only two levels, the personal and transpersonal, with the 
overlap being designated the perinatal. This is consistent with Grof's overall description and represents only a difference of emphasis. In this model, the term "perinatal" identifies not a distinct "level" but merely a region of interpenetration of two more fundamental modes of awareness. We might think of it as a standing wave that exists between the personal and transpersonal realms. It is a middle zone that functions partly as a bridge and partly as a buffer between two worlds. Awareness functions differently on either side of this zone, which must mediate and integrate these differences.

The advantage of shifting to this simpler model is primarily a gain in conceptual clarity. It emphasizes the fact that the perinatal stands "midway" between the personal and transpersonal levels and participates completely in both. That is to say, it is completely balanced in its makeup, fully partaking of both levels and performing discrete but integrated functions in each. The personal is not more fundamental to it than the transpersonal. When therapy progresses to this point, one's inner work is not necessarily centered on the birth trauma, though under certain conditions it may be. (I will return to this point later.) It is not a domain that makes primary sense in personal categories and less sense in transpersonal categories. Rather, it is an operational mode of consciousness in which the personal and transpersonal blend, sharing organizational patterns and structures. It is a mode in which the roots of individual consciousness intertwine with the forest floor of collective consciousness, where the ending of one and the beginning of the other fade until they disappear. Indeed, Grof's data on the perinatal indicated that the duality of "self" and "surround" is dissolved at the perinatal level and replaced by a holographic dance, in which self and surround move in rhythmic harmony, blending at deeper and deeper levels until they come to express a single design. During the perinatal phase of inner exploration, work may begin at the personal level, that is, the birth trauma, but it will always end at the collective, because the deathrebirth process consumes the categories of the personal and opens one to a larger surround as one's deeper reality.

Given its hybrid nature, our description of the perinatal will differ depending on whether we are looking at it from the personal or transpersonal side of the picture. From the personal perspective, the perinatal appears to be the basement of the personal unconscious, in which are kept the undigested fragments of those experiences which have most seriously threatened our physical and psychological integrity. It is the repository of the most serious challenges to our exist- 
ence. Small wonder, therefore, that fetal experiences would figure so largely here, as they derive from that period in our development when we were most vulnerable and most easily overwhelmed by our environment.

From the transpersonal perspective, however, the perinatal domain looks quite different. From this side the perinatal domain looks like the core of the insanity of atomized existence. It is the repository of our individual and collective attempts to live the lie of separateness, to pretend that we exist as autonomous beings and a separate species, isolated from the surrounding tapestry of existence. As such it represents the supreme philosophical ignorance and psychospiritual disease. The perinatal level represents the insanity of an entire species that has not yet used its self-awareness to penetrate to the roots of its existence, where it would discover its connection to the whole of life.

From the personal perspective, perinatal experience takes the form of being attacked and fighting back, of killing and being killed, until eventually we are completely and utterly destroyed. As we make the transition to the transpersonal perspective, however, these same experiences are discovered to be loving attempts to rescue us from our self-imposed prison of autonomous existence by dismantling that existence, to deliver us from our misguided efforts to cut ourselves off from the larger flow of life itself. Merciless attack from one perspective is merciful deliverance from another. We were not being killed at all but being birthed into a reality that is larger, more fundamental, and more "real" than physical reality.

If we want to unravel the logic of the appearance of collective suffering in perinatal contexts, I suggest that we begin by looking upon life the way it appears from the transpersonal perspective. Transpersonal experiences reveal connections that are hidden to the material world of discrete body/minds. For the sake of economy, let us review just two such experiences. The first appeared in The Adventure of Self-Discovery (Grof, 1988) and came from a high-dose LSD session.

What followed was a tremendous expansion of consciousness. I was out in interstellar space witnessing galaxies upon galaxies being created right in front of my eyes. I felt that I was moving faster than the speed of light. There were galaxies passing by me one after the other. I was approaching a central explosion of energy from which everything in the universe seemed to originate. It was the very Source of all that was created. As I moved closer and closer to this area, I felt the incandescent heat emanating from it. It was a gigantic furnace, the furnace of the universe. 
The sensation of heat was growing to unbelievable proportions, as was the intensity of the light. I recognized that the burning I was experiencing was the burning of the Purifying Fire. As I moved closer, I sensed that my identity was shifting from being the manifestation of this Energy to being the Energy itself. It seemed that I momentarily entered the very core of this Universal Furnace of cosmic creation. The experience was ecstatic and filled me with a sense of Infinite power.

I suddenly understood the principle underlying the organization of the cosmos. It was the Universal Consciousness playing out an endless series of dramas in a way we can see represented on the theater stage or in the movies. In this drama it plays a game of losing itself for the purpose of finding itself again. This Universal Consciousness would plunge into separation, rejection, pain, evil, agony, and darkness to experience the infinite joy of rediscovering its original pristine, safe, and blissful state. Its true identity is indivisible oneness, beyond negativity and dualities of any kind. To make the journey, it had to create the illusion of space, matter, and time and, together with it, the categories of evil, darkness, pain and destruction. (pp. 143-144)

The second account was quite similar to the first but with a different emphasis. It also came from a high-dose LSD session.

The experience then changed into an extremely powerful and moving experience of the Cosmic Tree. The energy became a massive tree of radiant energy suspended in space. Incredibly large, it was comprised entirely of light. The core of the tree was lost to the brilliant display, but limbs and leaves were visible around its edges. I experienced myself as one of its leaves. The lives of my family and close friends were leaves clustered around me on a small branch. All of our distinguishing characteristics, what made us the individuals we were, appeared from this perspective to be quite minor, almost arbitrary variations of this fundamental energy.

I was taken around the tree and shown how easy it was to move from one person's experience to another, and indeed it was ridiculously easy. Different lives around the globe were simply different experiences the tree was having. Choice governed all experience. Different beings who were all part of Being Itself had simply chosen these manifold experiences.

At this point I was the tree. Not that I was having the full range of its experience, but I knew myself to be this single, encompassing Consciousness. I knew that Its identity was my true identity. Though I had taken monism to heart years before, I was now actually experiencing the seamless flow of consciousness into crystallizations of embodiment. I was experiencing how consciousness manifests itself in separate forms while remaining unified. "So that's how it works," I said to myself. I knew that fundamentally there was only One Consciousness in the universe. From this perspective 
my individual identity and everyone else's appeared temporary and almost trivial. To experience my true Identity filled me with a profound sense of numinous encounter. (Grof and Bennett, 1992, pp. 165-166)

Readers of this journal will recognize the themes of interpenetration and inclusion that show up so consistently in deep NDEs. The world experienced here is not the world of discrete objects that we know in our ordinary, sensory mode of consciousness, but a deeper level of reality glimpsed through an extreme nonordinary state. Physical boundaries that appear so firm in the sensory mode appear exceptionally porous and even nonexistent in this state. The distinctions between self and other, between individual and species, between species and galaxy, and between galaxy and cosmos appear to hold only within specific limits. Beneath these boundaries runs a web that draws together the physical forms of life into configurations that escape physical sight. As Grof has repeatedly demonstrated in his books and as hundreds of thousands of NDErs have experienced for themselves, one can actually experience these subtle configurations. One can experience the Oneness underlying the physical world and learn first-hand that the truth of participatory interconnectedness subsumes the more relative truth of discreteness. Let us now return to examine perinatal experience within the context of these observations.

In perinatal experience one experiences personal anguish, of both a psychodynamic and fetal sort, intertwined with collective anguish. Sometimes this collective anguish focuses on various groups within human history, while at other times it embraces the human species as a whole, the planet, and even the galaxy. Whatever form it takes, it is always experienced as an expansion of identity. If not in the beginning, it always moves in this direction with repetition. That is, perinatal pain may initially be experienced as someone else's pain, as lying "out there" while I am "in here" experiencing it. Eventually, however, this defense breaks down as the boundary between "in here" and "out there" dissolves and the pain becomes completely appropriated. At this point it is not a personal " $\mathrm{I}$ " experiencing, for example, the anguish of thousands of soldiers who have died on the battlefields of history, but something larger than personal consciousness.

It is important to grasp the significance of not only the extension of consciousness that has taken place but the coherence of this extension with one's ordinary self-awareness. One's awareness can open to previously unbelievable limits, but this enlargement always begins 
with and is coherent with one's awareness as an individual human being. Repeated experience of the perinatal domain gives one access to a mode of consciousness in which the boundaries of one's body/mind identity are systematically enlarged to encompass larger and larger aspects of human and planetary history. For a time I actually am these thousands of soldiers. Their experience is my experience. I am millions of persons dying of starvation and neglect. I am a planet convulsing in volcanic explosion.

The conclusion that seems to follow from these observations is this: Therapy heals the patient present. If the "patient" in these intense states of awareness has expanded beyond the individual person, we must speculate that the healing realized through these exercises also reaches beyond the individual person. If the awareness experiencing these ordeals is genuinely beyond the personal level, as many subjects have testified, then perhaps the healing that is taking place is also focused beyond the personal level. The patient at this point might no longer be just the individual subject but something larger.

Here we have a riddle to solve. A therapeutic regimen that was initiated by an individual person presumably for his or her individual benefit begins to move beyond the life experience of that one person (even his or her extended karmic life) and to engage the pain of the species. It does so repeatedly and in a systematic fashion, activating collective forms of anguish of massive proportions. The fact that we are accustomed to thinking of psychotherapy primarily in terms of the individual, combined with the fact that these therapies do indeed benefit the individual enormously, have conspired to blind us to the possibility that these experiences might also have a therapeutic impact on systems that transcend the individual. Furthermore, it is not immediately obvious who or what this enlarged "patient" might be. If the therapeutic impact of these experiences reaches beyond the individual, to what does it reach? How should we conceptualize this "something larger" that seems so deeply involved in our healing process?

This is where Rupert Sheldrake's theory of formative causation and morphic fields might help us. Sheldrake's presentation is subtle and complex, and I shall restrict myself, with obvious oversimplification, to highlighting the implications of his theory for our immediate problem. 


\section{Sheldrake's Concept of Morphic Fields}

Sheldrake uses the term "morphic fields" as a general category that includes several different types of fields, including morphogenetic fields, behavioral fields, social and cultural fields, and mental fields. Here I am primarily concerned with the field that Sheldrake calls the "group mind" (Sheldrake, 1989, pp. 247-248).

Sheldrake has argued in his several books $(1981,1989,1991)$ that the individual members of every species are networked through an encompassing species-mind that constitutes the dynamic blueprint of that species. Sheldrake's innovation has been to suggest not only that this field contains the blueprint of the species's physical form and behavioral tendencies, but that it collects and incorporates into itself the new experiences of its individual members, constantly synthesizing at a central level the diverse experiences of its physically discrete parts. Thus, morphic fields can be thought of as mediating between the parts and the whole of a species, and also between the past and the future of a species. They are seen as extending the past into the present while simultaneously collecting experiences from the present that allow innovations in the future. In contrast to Carl Jung's earlier concept of the collective unconscious, Sheldrake insists that his theory is empirically testable because we can in principle test the rate at which a new skill is acquired by a species. The jury will be out on this one for some time, but early reports of attempts to test his innovative hypothesis are encouraging (Sheldrake, 1989).

Sheldrake suggests that between the individual and the morphic field of the species, numerous intermediate fields exist that correspond to various subgroupings that the individual is part of, such as family, community, nation, race, and culture. The species-field is in turn nested in a series of larger fields that encompass, for example, the planet, the solar system, the galaxy, and so on. Like Gregory Bateson (1972, 1979), Sheldrake puts forth a vision of fields nested within fields nested within fields, with lines of communication running from the largest to the smallest and back again.

Sheldrake's theory suggests that the mental processes we see operating within an individual human being might be paralleled by similar processes operating in the species-mind, making allowances for the enormous differences involved. Thus, just as we remember in a coherent fashion the experiences of our individual body/mind, the species-mind would remember its vast experiences. Just as the 
integration and management of our individual experiences reflects intelligence and choice, the species-mind might possess the same capacities on a higher order. Similarly, the larger system of which the human species is a part might also possess these capacities, and so on. We soon lose track of the progression, but we do not need to know the map of the entire terrain in order to unravel the logic of transpersonal perinatal experiences, which is our task here.

\section{Morphic Fields and Perinatal Experience}

It is striking how well Sheldrake's hypothesis of morphic fields meshes with Grof's experiential data. If we combine their perspectives, new possibilities emerge for understanding the emergence of transpersonal suffering in the context of personal inner work. Very simply put, it would appear that something larger than the individual, yet something that the individual is part of, takes advantage of the opportunity provided it by the individual to heal itself. Following Sheldrake, I suggest that this "something larger" might be the species-mind, a consciousness that collects, retains, and integrates the experiences of its many members. This hypothesis derives from a phenomenological analysis of perinatal experience and remains speculative until such time as Sheldrake's theory is empirically confirmed.

If we assume for the moment that the dynamics of this speciesmind do parallel the dynamics of the personal psyche at least to some degree, we can speculate that just as problematic experiences can collect and block the healthy functioning of the individual, similar blockages might also occur at the collective level. This suggests that the unresolved human anguish of history might still be active in the memory of the species-mind, burdening its life just as our individual unresolved anguish burdens ours. Continuing the parallel, if conscious engagement of previously unresolved pain brings therapeutic release at the personal level, the same might also occur at the species-level. Normally we would expect that such an engagement and release would take the form of mass social movements or cultural shifts in which large numbers of persons in some way or another confront and absorb some painful legacy from their collective past. Within the context of intense experiential psychotherapy, however, a new possibility seems to be emerging. 
As we follow the roots of our pain in LSD-assisted psychotherapy, we discover that our individual suffering is embedded in a historical web of suffering. The life of the individual appears to crystalize trends that reach beyond the individual, both socially and historically. As our inner life unfolds in the psychedelic arena, we spontaneously find ourselves being opened beyond our individual existence to encompass various aspects of a larger surround, and this surround is, most immediately, the historical experience of our species. Furthermore, the experience is not one of becoming something other than what we are, but rather of reaching into deeper levels of what we already are. We do not take on the species-mind, but rather open to that part of our being where we already are the species-mind. And when this happens, we suffer.

Some suffer more than others, but all suffer. The extreme nature of this suffering can be explained partially in terms of the principle of summation, reflecting the insight that the psyche stores experience in experiential aggregates (COEX systems) whose total energy is the sum of all its parts. If we include in these complex amalgams trauma from previous incarnations, we significantly expand the theoretical explanation of the extreme levels of anguish that can be involved. However, I believe that the principle of summation by itself is insufficient to explain the full scope of perinatal anguish. There are two reasons for drawing this conclusion. First, the sheer quantity of pain can exceed anything that could reasonably be explained in terms of even a long succession of incarnations. Even more telling, however, is the peculiar quality of the suffering. This pain is inherently collective. Its organizational patterns are the patterns of a species, not an individual. Its sweep is the sweep of whole groups of people arching against the backdrop of millennia. As Grof has demonstrated, there are somatic and emotional parallels between this pain and the personal pain one is simultaneously experiencing. Going beyond Grof, however, we should theorize that there is at least a two-tiered structure of healing operating: one at the level of the individual, and a second at the level of the species.

At this point I want to acknowledge what may be a discrepancy between Sheldrake's concept of morphic resonance and my use of that concept. The notion that an individual can mediate cathartic release at the species level suggests the transfer of some form of mental or psychic energy, understanding that the term "energy" is being used somewhat metaphorically in this context. By contrast, Sheldrake holds that morphic resonance is unlike other forms of resonance, such 
as acoustic and electro-magnetic resonance, in that it does not involve a transfer of energy from one system to another, but rather a "nonenergetic transfer of information" $(1989$, p. 108). At this point it is not clear to me whether this discrepancy can be removed by semantic clarification or whether we should propose that at least some forms of morphic resonance involve an energetic transfer of information.

These two tiers of healing, at the individual and species level, are often so deeply intertwined in perinatal experience that it is difficult to distinguish them. However, in Realms of the Human Unconscious (1975), Grof presented an account of ego-death in which the individual and collective aspects of the process were unusually well differentiated. The term "ego-death" actually applies more accurately to the personal tier than the transpersonal tier. Suitable terminology for the comparable collective transition is as yet lacking and would have to reflect the varied forms it can take. This account allows us to mark both the parallels and the differences between the two tiers.

. . . [S]uddenly my wild symphony took over. It was as if I were first at the top of a roller coaster gradually being drawn over the precipice, losing control, and being quite unable to arrest the downward plunge that I could see was ahead of me. One analogy I thought of was that this was like swallowing a keg of dynamite with the fuse already lit. The fuse was inaccessible, the dynamite was going to explode, and there was nothing I could do about it. The last thing I can remember hearing before my roller coaster began going down was music that sounded as though it came from a million earphones. My head was enormous at this time, and I had a thousand ears, each one with a different headset on, each earphone bringing in different music. This was the greatest confusion I have ever felt in my life. I was aware of being on the couch; I was dying right there and there was nothing I could do about it. Every time I would try to stop it, I became panicky and terror-ridden. The only thing was to go toward it. The words "trust and obey," "trust and obey" came through to me and in what seemed like a flash, I was no longer lying on the couch and did not have my present identity. Several scenes began to take place; it seemed as though they happened all at once, but let me string them out to try to make some sense of them.

The first scene was plunging down into a swamp filled with hideous creatures. These creatures were moving toward me, but they were unable to reach me. All of a sudden the swamp was transformed into a canal in Venice just under the Bridge of Sighs. My family, my wife, and my children were standing on the bridge looking down at me in this swamp. There was no expression on their faces; they were simply standing there looking at me. 
The best way of describing this roller coaster and this entrance into the loss of control would be to compare it to walking on a slippery, very slippery surface. There would be surfaces all over the place and finally all of them would become slippery and there would be nothing left to hold on to. One was slipping, slipping and going further and further down into oblivion. The scene that finally completed my death was a very horrible scene in a square of a medieval town. The square was surrounded by Gothic cathedral facades and from the statue niches in these facades and from the gargoyle downspouts in the eaves animals, persons, animal-human combinations, devils, spirits-all the figures that one observes in the paintings of Hieronymus Bosch-came down from the cathedrals into the square and moved in on me. While the animals, the humans, the demons pressed in upon me in the square before these Gothic cathedrals, I began to experience intense agony and pain, panic, terror, and horror. There was a line of pressure between the temples of my head, and I was dying. I was absolutely certain of this-I was dying, and I died. My death was completed when the pressures overwhelmed me, and I was expelled into another world.

At this point in the narrative, a reader familiar with Grof's work might justifiably expect the next paragraph to describe a scene of spiritual rebirth, for this man has undergone a profound ego-death experience. Aspects of fetal experience echo through his account: the enlarged head, confusion and loss of control, the downward plunge, a slippery, slimy environment, a Venetian "canal" known for its polluted waters, and pressure across the temples. There is nothing left to break down at the personal level; his death appears complete. Nevertheless, he does not make the transition to rebirth yet. He continues:

It turned out that this outer world was to be a continuation of deaths at a very different level, however. Now the panic, the terror were all gone; all that was left was the anguish and the pain as I participated in the death of all men. I began to experience the passion of our Lord Jesus Christ. I was Christ, but I was also everyone as Christ and all men died as we made our way in the dirgelike procession toward Golgotha. At this time in my experience there was no longer any confusion; the visions were perfectly clear. The pain was intense, and the sorrow was just, just agonizing. It was at this point that a blood tear from the face of God began to flow. I did not see the face of God, but his tear began to flow, and it began to flow out over the world as God himself participated in the death of all men and in the suffering of all men. The sorrow of this moment is still so intense that it is difficult for me to speak of it. We moved toward Golgotha, and there in agony greater than any I have ever experienced, I was crucified with Christ and all men on the cross. I was Christ, and I was crucified, and I died. 
This second death is markedly different from the first. The confusion and panic have vanished, his experiential field is clear, and the agony has intensified as he moves to a collective level in which he becomes the entire human race. Religious imagery consummates this expanded identity as he experiences a death that touches all humanity and seems to involve even God. I think we should take this man at his word and honor the distinctions he has so carefully drawn. This second death is not a mere recasting of ego-death against a larger background, but a new movement in the death-rebirth symphony. Something larger is dying at this level, something that seems to involve and affect the entire species. The rebirth that follows continues in this collective vein:

When all men died on the cross, there began the most heavenly music I have ever heard in my entire life: it was incredibly beautiful. It was the voice of angels singing, and we began slowly to rise. This was again almost like birth; the death on the cross happened, and there was a swishing sound as the wind rushed from the cross into another world. The gradual rising of all men began to take place. These were great processions in enormous cathedrals - candles and light and gold and incense, all moving up. I had no sense of my personal existence at this time. I was in all the processions, and all the processions were in me; I was every man and every man began to rise. The awe and splendor of this rising was almost beyond description. We were rising toward light, higher and higher, through majestic white marble pillars. We left behind the blues, the greens, the reds, and the purples, the gold of the cathedrals, and the royal garbs of some of the people. We rose into whiteness; the columns we were rising between were white and pure. The music was soaring, everyone was singing, and then there occurred a vision.

This vision has an entirely different feeling about it from anything else I experienced in the whole LSD session. It still feels like a vision-as if a vision were actually given to me-it is so real. The resurrection garment of our Lord touched me. Yet you have to understand: it did not touch me; it touched all men and yet in touching all men it touched me. When it touched, several things happened at once, as they did many times during this experience. We all became very small-as small as a cell, as small as an atom. We all became very humble and bowed down. I was filled with peace and feelings of joy and love; I loved God completely. While this was happening, the touch of the garment was like a high voltage wire. Everything exploded, and it exploded us into the highest place there is - the place of absolute light. It was silent; there was no music; it was pure light. It was like being at the very center of the energy source. It was like being in God-not just in God's presence, but in God and participating in God. (Grof, 1975, pp. 145-148) 
This powerful visionary experience allows us to push our analysis one step further. As already noted, if therapy is continued long enough and at sufficiently deep levels, perinatal suffering eventually ends. On a personal model of the psyche, this makes sense because we assume that one's inner distress is ultimately finite and therefore exhaustible. On the model we are using here, however, it is not this simple. Given the hypothesis of morphic field involvement, we must try to explain the fact that the suffering ends for an individual even though there is obviously more suffering in the species-mind waiting for release. If the individual and the species are so intimately interwoven in their quest for wholeness, how is it that they become separated?

The key to solving this problem is to postulate that the therapeutic value of the individual to the species-mind actually takes two forms, not just one as suggested thus far. The first is the cathartic release of negative experiences. The second is the direct infusion of positive experiences into collective awareness. If it is the case that experiencing the collective suffering of the species in some way mediates experience for the species, by the same logic it would follow that positive transpersonal experiences also directly benefit the species as a whole.

The individual's initial therapeutic contribution to the species-mind occurs while he or she is clearing problematic experiences from the personal psyche. The engagement of personal distress, including fetal distress, in these augmented states of consciousness appears to create a bridge to transpersonal levels through some mechanism of morphic resonance that precipitates therapeutic release at these levels. When a person has exhausted his or her individual pain, however, there is nothing within the individual that allows this resonance with the pain in the surrounding species-mind to be established. At this point the individual does not detach him- or herself from the species, as if that were possible, but rather the therapeutic role for the species shifts from that of cathartic release to the cultivation of positive transpersonal experiences, such as the spiritual vision just quoted.

A careful examination of the above vision supports this line of thought. The subject was clearly struggling to articulate a subtle but important aspect of his experience when he explains, "The resurrection garment of our Lord touched me. Yet you have to understand: it did not touch me; it touched all men." His deeply felt sense of expanded participation causes him to shift spontaneously back and forth between "we" and "I." His narrative is completely in accord with the theory of morphic fields. In this state of expanded awareness, he is both himself and all humanity, and thus through him all hu- 
manity participates in the uplifting transformation he describes so eloquently.

To this example we can add the observation that many transpersonal experiences in advanced LSD sessions seem clearly to have an educative function. This becomes evident when a particular insight or experience is developed in stages across an extended series of sessions. Each session seems to begin where the last session ended, and the themes repeat themselves until they have been unfolded and assimilated. I suggest that we underestimate the purpose and scope of this instruction if we do not recognize that it is aimed not just at the individual but in some way at the entire species or at some subset of the species. Something appears to be using these privileged states of awareness to gain leverage on the entire species, not just one person.

\section{Summary}

To sum up the hypothesis put forward here, I propose that the perinatal dimension of consciousness is as inherently transpersonal as it is personal, that its collective aspects are not secondary to its fetal aspects but rather just as essential. Accordingly, I further propose that the therapeutic benefit of bringing into consciousness the painful collective experiences that regularly surface during the perinatal stage of LSD psychotherapy extends beyond the individual to the human species as a whole. The interpenetration of the consciousness of the individual and the species surfaces in experientially oriented sessions not as an exception to the rule but as a dramatic manifestation of the rule of morphic fields. These heightened states of awareness do not make possible what is otherwise impossible, but rather amplify and make obvious a connection that is usually so subtle as to escape detection. While having jarring implications for our conventional understanding of human identity, this interpretation of perinatal experience is surprisingly consistent with themes emerging in quantum theory (Bohm, 1980).

\section{Possible Explanations for Grof's Tilt Toward the Personal}

At this point, we might ask this question: Why would Grof, who has such a deep grasp of transpersonal dynamics, have produced a 
description of perinatal dynamics so tilted in the direction of personal psychology? I can think of two possible reasons.

The first and, I think, more important reason has to do with the historical context in which Grof began to publish. Grof worked out the fundamental outline of his paradigm during his 10 years at the Psychiatric Research Institute of Prague (1956-65) and refined them during his six years at Spring Grove Hospital in Baltimore, Maryland (1967-73). Clinical psychiatry was dominated in those years by Freudian thinking with few theoreticians reaching beyond an eclectic synthesis of psychodynamic theory to map the personal unconscious. If Grof was to find any audience among his peers, he would have had to cast his discoveries in categories they could understand, even while inviting them to transcend those categories. Such an approach would have led to emphasizing the fetal aspects of perinatal experience, as a logical extension of psychodynamic theory, over the transpersonal aspects. Similarly, it would have continued the traditional focus on the individual as the only beneficiary of this augmented form of therapy.

In a personal communication (October 16, 1991), Grof has stated that his presentation of perinatal dynamics was primarily influenced by these strategic considerations, and I see no reason to doubt this. There may, however, have been a second, subtler contributing factor, a factor that is relevant to our proposal to understand frightening NDEs as essentially perinatal experience.

The clinical protocol at the Psychiatric Institute of Prague was "psycholytic" therapy, calling for a long series of relatively low dose sessions, using from 75 to 300 micrograms of LSD. In this form of therapy, the unconscious was stripped layer by layer, peeling away the COEX systems and perinatal matrices in smaller increments. While the deep unconscious functions holographically, making it possible for any one session to contain material from all three levels, consciousness is nevertheless less mobilized in low dose sessions than in high dose sessions. Later, at Spring Grove, the clinical protocol was "psychedelic" or high dose therapy, using from 300 to $1500 \mathrm{mi}$ crograms, but treatment was restricted to a maximum of three sessions. The goal of these few sessions was to facilitate a deep mystical experience, not to work through conflicts rooted in the psychodynamic and perinatal levels. For a fuller description of the differences between psycholytic and psychedelic therapy, see Grof, 1980; for more on the Spring Grove program, see Grof, 1975; and Grof and Halifax, 1977. 
The question of dose is significant here for the following reason. A close reading of Grof's material and a careful examination of my own experience lead me to hypothesize that a psycholytic approach to therapy will tend to emphasize the personal side of the perinatal interface while a psychedelic approach will emphasize its transpersonal dynamics. Generalizations of this sort are risky because many variables influence the content of an individual session, including the personality of the subject, the experience of the therapist, the set and setting of the session, the number of previous sessions, and so on (Grof, 1980). Nevertheless, some observations on the influence of dose are possible.

A low LSD dose results in a less amplified and less catalyzed state of awareness that, in turn, results in, all other things being equal, a weaker resonance between personal and transpersonal levels during the perinatal phase of work. A weaker resonance leads to fewer transpersonal elements being drawn into the therapeutic process. As a result, perinatal sequences would naturally tend to be more centered on reliving one's biological birth. A higher dose of LSD, on the other hand, produces a more highly mobilized state of awareness, encouraging a stronger resonance with the surrounding transpersonal domain. In psychedelic sessions, which are designed not to bypass but to engage and resolve conflict, transpersonal elements would tend to be more prominent in one's perinatal experience and could, over the course of therapy, completely overshadow the fetal aspects of the death-rebirth process.

Grof has stated in several places that it was his work at Prague that provided him with the detailed insights into the many layers of consciousness and their interaction that we see in his paradigm (e.g., Grof, 1975). During the critical years when he was developing his theories, therefore, his primary data base derived from psycholytic therapy. If my conjecture concerning the influence of dose on the slant of perinatal experience is correct, this might have further encouraged a description of perinatal dynamics tilted toward the personal.

Whatever occurred in the past, it seems important at this stage of the discussion to include a consideration of dosage into any comprehensive account of how the perinatal interface manifests itself. My personal observations have been that in a sustained regimen of psychedelic therapy-a treatment option Grof did not discuss at any length in his corpus-transpersonal experiences such as those described in the quote in the opening section of this paper can so domi- 
nate perinatal experience as to dwarf the significance of one's biological birth. Fetal aspects may appear as a small vignette projected against thundering transpersonal sequences. Like a solo violin playing against a massive orchestra, the two intertwine, but in this instance the orchestra carries the dominant theme and swallows the violin entirely.

The relevance of this discussion of treatment protocols to a perinatal interpretation of frightening NDEs is this. Phenomenologically, frightening NDEs appear to resemble the perinatal experiences that emerge in higher dose contexts rather than lower dose contexts. In frightening NDEs what usually stand out are the collective, transpersonal perinatal themes, not the personal, fetal themes. The absence of fetal themes does not by itself speak against a perinatal interpretation of frightening NDEs, but rather underscores the fact that a frightening NDE is a highly energized state of consciousness in which the NDErs have moved far beyond the rim of personal consciousness. If they have not been catapulted completely into the light, they have nevertheless been thrown outside the boundaries of the individual psyche, deep into the collective waters of the species mind.

\section{Frightening Near-Death Experiences and Morphic Fields}

In my earlier paper (Bache, 1994), I observed that someone who has experienced a frightening NDE is often both terrified and ashamed: terrified to discover that realms of such dread and sorrow actually exist and ashamed to have been denied the ecstatic encounter with the light. I suggested that both reactions might be therapeutically softened by helping the NDEr understand that the frightening NDE is not an alternative NDE but an incomplete NDE. It has less to do with the subject's existential worth than with the as yet hidden variables that determine the strength and intensity of one's NDE.

To these observations we can now add the additional insight that what one encounters in a frightening NDE goes far beyond personal intrapsychic realities. In this experience one is confronting aspects of the collective species mind, glimpsing undigested fragments of our species' historical experience, species COEX systems, if you will. If there is a patient here, it is the species as a whole, not just this one 
person. If there is a lesson to be learned from these encounters, it is a lesson that we must learn collectively, not just individually.

The trauma of these frightening episodes can further be softened by helping the NDEr understand the possible beneficial effect such confrontations may have for the species as a whole, however tentatively and incompletely we grasp the dynamics involved. If recalling repressed trauma helps heal the individual who remembers it, we have some precedent for thinking that when a member of a species brings some aspect of its collective anguish into conscious awareness, it has a healing effect that is distributed through the species as a whole. Just as Kenneth Ring (1984) envisioned the possible enlightening effect of positive near-death experiences on the entire species by means of morphic resonance, so likewise we might suggest to the person who has had a frightening NDE that his or her ordeal might have a small cleansing effect on the entire species mind. Though we may not be able to measure the size of the wave that moves out across waters of the collective unconscious, we have reasons for thinking that a wave has been set in motion.

Lastly, we might remind the NDEr that the notion that an individual can suffer on behalf of others finds many precedents in the world's spiritual traditions. In the West one is reminded of the songs of the "Suffering Servant" in Deutero-Isaiah, which became the theological foundation for the "sacrificial death" interpretation of Jesus' crucifixion. In the East we have the eclipsing of the Theravadan ideal of the arahant, who seeks only individual enlightenment, by the Mahayana ideal of the bodhisattva, who seeks the enlightenment of all sentient beings. The experience of nirvana is said to destroy the illusion of separate existence. If this is true, the everything we do might affect everyone else, including what we do during a frightening NDE.

\section{References}

Bache, C. M. (1994). A perinatal interpretation of frightening near-death experiences: A dialogue with Kenneth Ring. Journal of Near-Death Studies, 13, 25-45.

Bateson, G. (1972). Steps to an ecology of mind: Collected essays in anthropology, psy. chiatry, evolution, and epistemology. San Francisco, CA: Chandler.

Bateson, G. (1979). Mind and nature: A necessary unity. New York, NY: Dutton.

Bohm, D. (1980). Wholeness and the implicate order. London, England: Routledge and Kegan Paul.

Grof, S. (1975). Realms of the human unconscious: Observations from LSD psychotherapy. New York, NY: Viking. 
Grof, S. (1980). LSD psychotherapy. Pomona, CA: Hunter House.

Grof, S. (1985). Beyond the brain: Birth, death, and transcendence in psychotherapy. Albany, NY: State University of New York Press.

Grof, S. (1988). The adventure of self-discovery. Albany, NY: State University of New York Press.

Grof, S., and Bennett, H. Z. (1992). The holotropic mind. New York, NY: HarperCollins. Grof, S., and Halifax, J. (1977). The human encounter with death. New York, NY: Dutton.

Sheldrake, K. (1981). A new science of life: The hypothesis of causative formation. Los Angeles, CA: Tarcher.

Sheldrake, R. (1989). The presence of the past. New York, NY: Vintage Books.

Sheldrake, R. (1991). The rebirth of nature. New York, NY: Bantam. 